Research Paper

\title{
Thickness of Palatal Masticatory Mucosa and Its Relationship with Different Parameters in Turkish Subjects
}

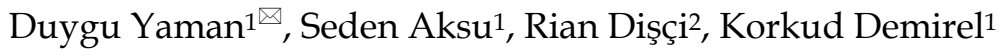 \\ 1. Department of Periodontology, Faculty of Dentistry, Istanbul University, Istanbul, TURKEY \\ 2. Department of Biostatistics and Medical Information, Faculty of Medicine, Istanbul University, Istanbul, TURKEY
}

$\bowtie$ Corresponding author: Duygu Yaman, DDS, PhD, Istanbul University Faculty of Dentistry, Department of Periodontology, 34093 Capa, Istanbul / TURKEY. E-mail: duyguyaman@yahoo.com; Tel: +90 2124142020 - 30253; Fax: +90 2125340807

(c) Ivyspring International Publisher. This is an open-access article distributed under the terms of the Creative Commons License (http://creativecommons.org/ licenses/by-nc-nd/3.0/). Reproduction is permitted for personal, noncommercial use, provided that the article is in whole, unmodified, and properly cited.

Received: 2014.03.14; Accepted: 2014.07.02; Published: 2014.07.20

\begin{abstract}
Background: The aim of the study was to clinically investigate the mucosal variations in different parts of hard palate subject to soft tissue harvesting and its relationship with selected parameters in patients with gingival recessions.

Materials \& Methods: Fifty periodontally healthy, dentate subjects ( 13 males) with gingival recessions were enrolled into the study. After initial periodontal therapy they were scheduled for surgical procedures. Palatal masticatory mucosa of five teeth was evaluated at five different points from the gingival margin and two points on the buccal gingival mucosa were evaluated on the day of surgical intervention via bone sounding method. Totally 27 assessments were performed for each patient.

Results: The overall mean thickness of palatal masticatory mucosa (PMM) was $2.55 \pm 0.49 \mathrm{~mm}$. The mean mid-facial gingival thickness was $1 . I I \pm 0.39 \mathrm{~mm}$. The PMM showed an increase towards the posterior and raphe palatina. No difference was observed between genders, and no association of body mass index (BMI) and age with PMM was determined. An association was observed between the thicknesses of mid-facial gingival and palatal masticatory mucosa.

Conclusion: The thickness of PMM in this study seems to be less than other reports possibly due to ethnicity or measurement design. Canine and premolar region reveals higher thickness values, and the increase in the tissue thickness towards the midline should also been taken into consideration. Clinicians planning soft tissue harvesting from the palate should take this variation into consideration. In this regard transmucosal probing of the donor site may provide valuable information where considerable variation exists.
\end{abstract}

Key words: palatal masticatory mucosa, Turkish subjects

\section{Introduction}

The masticatory mucosa consists of buccal gingiva and the mucosa of the hard palate which are two distinct soft tissues [1] in the oral cavity. The palatal masticatory mucosa (PMM) is considered to be the main donor area of soft tissue grafts addressed for periodontal plastic surgery [2]. The volume and characteristics of tissue that can be obtained from this area are important [3] in determining appropriate treatment modality and can affect surgical outcome $[4,5]$. Therefore detailed information about thickness of the PMM would provide significant benefit in the selection of an appropriate region for harvesting grafts [5-7]. Thickness of PMM had previously been investigated and intra- and inter-individual variations 
have been reported $[7,8]$.

There are invasive and non-invasive methods of mucosal thickness evaluation. Transmucosal probing the bone with a penetrating instrument [9-13] or tissue collection for histometric evaluation [14] are considered to be invasive, whereas ultrasonic and tomographic methods are non-invasive [1, 6, 15-18]. However, the radiation effect of cone beam computerized tomography (CBCT), although reported to be low, should also be noted [17]. "Bone sounding" is a direct measurement method giving one of the most reliable results regarding the thickness of the PMM. A few of studies in the literature used this method in partly or fully dentate patients [10-13]. Some of these studies suggested the thickness of the PMM to be related with some parameters such as body mass index (BMI) [12, 13], age [11], gender [13], or gingival biotype while others failed to show such relationship [10,11].

The term "biotype" or "gingival biotype" was introduced by Seibert and Lindhe [19] to describe the thickness of the gingiva in a bucco-lingual dimension. It has been considered to be related to variables such as the thickness of underlying bone plate, tooth form [20], genetics [21, 22], age, gender, and dental arch [23]. A direct correlation has been suggested between gingival biotype and the susceptibility to gingival recession following surgical or restorative procedures [24]. There are studies showing a relationship between palatal and gingival masticatory mucosa in terms of thickness $[7,8,14]$. This may indicate a possible association between these two factors, the existence of gingival recession and thinner palatal masticatory mucosa. There are no studies evaluating the thickness of masticatory mucosa in patients with gingival recessions using a direct measurement method.

Because of limited and inconsistent information on individual and regional differences of thickness of the PMM, possible factors affecting this thickness, and its importance in harvesting grafts for recession treatment, the primary goal of this study was to determine the thickness of palatal masticatory mucosa in Turkish subjects with gingival recessions by a bone sounding technique. The associations of BMI, gender, age and gingival biotype with the thickness of PMM were also investigated.

\section{Material and Methods}

Fifty healthy Turkish patients (13 males and 37 females) referred to periodontology department with the chief complain of gingival recession were enrolled into this study. They were in an age range of 16-47 years (mean: $27.4 \pm 7.80$ years). Informed consents were obtained from all individuals and all measurements were performed in accordance with the Helsinki Declaration of 1975, as revised in 2002 with the ap- proval of the Local Ethics Committee of Medicine Faculty of Istanbul University.

Patients with complete maxillary dentition from the maxillary canine to the second molar with healthy periodontal tissues except for gingival recessions were included in the study. The exclusion criteria were: previous surgical intervention of the affected area, history or presence of pathology or at PMM and facial gingiva, periodontal disease, implants, orthodontic retainers and prosthetic appliances at the site of evaluation, tooth mal-alignment, use of any medication possibly affecting the periodontal tissues, presence of pregnancy, lactation and any systemic disease that can affect the mucosal structure in the oral cavity.

After initial examination, all patients were scheduled for surgical procedures for root coverage using bilaminar techniques. All measurements were performed before the surgery by the same investigator (S.A). The PMM thickness measurements were recorded at canines $(\mathrm{C})$, premolars $(\mathrm{P} 1, \mathrm{P} 2)$ and molars (M1, M2) at 5 different levels in the palate, the first being on the corresponding palatal mucosal surface of the sulcus bottom (S), and followed at distances of 2, 4,6 and $8 \mathrm{~mm}$ from the gingival margin (Fig. 1). The thickness of buccal masticatory mucosa was measured at points $2 \mathrm{~mm}$ apical to the gingival margin of maxillary central incisors, whereas the thickness of interproximal gingiva at the level of papilla base of the same tooth.
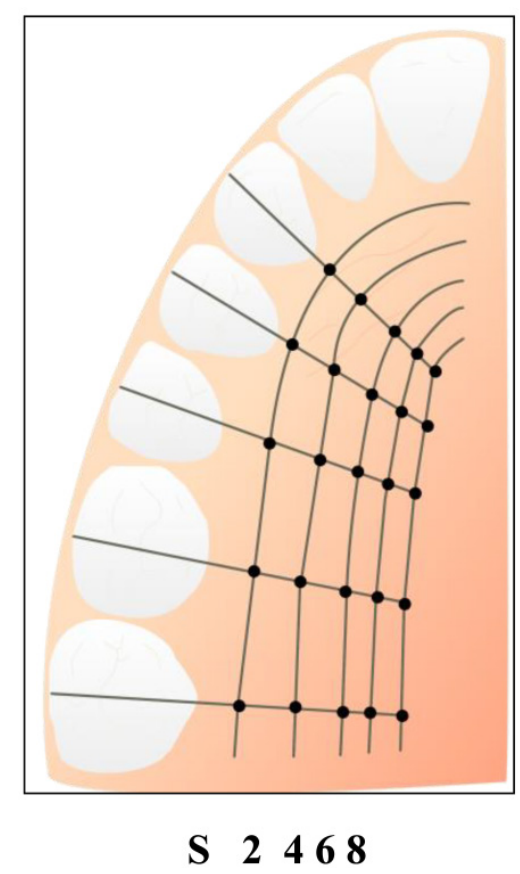

Figure I. Measurement of the palatal masticatory mucosa were performed from maxillary canine to second molar on one side at sulcus level(S) and 2,4,6 and $8 \mathrm{~mm}$ from the gingival margin. 
Twenty minutes after the local anesthetic injection, the distances between the reference points were determined with a William's type periodontal probe as described by Studer et al. [10], and marked by a marking pen, and a sterile endodontic reamer (\#20) with a silicone stop was used to penetrate the mucosal surface perpendicular to bone. When the measurement point was on the rugae area, the base of the rugae was chosen as the measurement point. The extent of penetration was measured by using a calliper to the nearest $0.1 \mathrm{~mm}$. In total, 27 measurements were obtained from each participant.

The BMI was calculated by measuring the height in centimetres and the weight in kilograms using Quetelet's formula.

Quetelet's index: weight $(\mathrm{kg}) /$ height square (meters).

\section{Statistical Evaluation}

Mean, median, with standard deviations of masticatory mucosa thickness in different measurement points were calculated with descriptive statistics. Mann-Whitney $U$ test was performed to evaluate the difference in mucosal thickness between the genders at each measurement point. The median BMI was calculated and the sample separated into two groups accordingly.

Relations between continuous variables were determined with Pearson correlation coefficient. Two-tailed $p$ value $(p=0.05)$ was used for all comparisons.

\section{Results}

\section{The palatal masticatory mucosa}

The overall mean thickness of PMM was $2.55 \pm 0.49 \mathrm{~mm}$ with a range of $1.54 \mathrm{~mm}-3.76 \mathrm{~mm}$. The difference was not statistically significant for gender, females $(2.50 \pm 0.45 \mathrm{~mm})$ and males $(2.72 \pm 0.59 \mathrm{~mm})$ $(p>0.05)$. The mean thicknesses in respect to tooth types were $2.48 \pm 0.51 \mathrm{~mm}$ for $\mathrm{C}, 2.64 \pm 0.48 \mathrm{~mm}$ for $\mathrm{P} 1$, $2.75 \pm 0.55 \mathrm{~mm}$ for $\mathrm{P} 2,2.26 \pm 0.56 \mathrm{~mm}$ for $\mathrm{M} 1$, and $2.64 \pm 0.83 \mathrm{~mm}$ for M2 sites. The mean value was the thickest at P2 region while it was the thinnest at M1 region. There was a tendency for an overall increase in mean thickness up to P2, a decrease at M1, and an increase again at M2. Table 1 and Fig. 2 show the mean thickness, median, min-max values and standard deviations of the PMM with respect to teeth, level of measurement and gender. The tissue thickness at the sulcus level of canine region was the thinnest $(1.54 \pm 0.53 \mathrm{~mm})$ among all measured points while $8 \mathrm{~mm}$ line of P2 region was the thickest $(3.76 \pm 0.87 \mathrm{~mm})$. It was similar in women and men except at sulcus level of P1 region, which was the thinnest in men. Thickness of the PMM seemed to increase as moving medianly (Fig 1,3). The $8 \mathrm{~mm}$ line was the only measurement height where the women's mean PMM thickness was found to be significantly thinner than those of men $(\mathrm{p}=0.02)$.

Table I. Mean and median thicknesses with standard deviations of the PMM with respect to teeth, measurement levels and gender.

\begin{tabular}{|c|c|c|c|c|c|c|c|c|c|c|c|c|c|c|c|c|c|c|c|c|c|c|c|c|c|}
\hline \multirow{2}{*}{$\begin{array}{l}\text { Position } \\
\begin{array}{l}\text { Measurement } \\
\text { point }\end{array}\end{array}$} & \multicolumn{5}{|c|}{ C } & \multicolumn{5}{|c|}{ P1 } & \multicolumn{5}{|c|}{ P2 } & \multicolumn{5}{|c|}{ M1 } & \multicolumn{5}{|c|}{ M2 } \\
\hline & $\mathrm{S}$ & 2.0 & 4.0 & 6.0 & 8.0 & $\mathrm{~S}$ & 2.0 & 4.0 & 6.0 & 8.0 & $S$ & 2.0 & 4.0 & 6.0 & 8.0 & S & 2.0 & 4.0 & 6.0 & 8.0 & $S$ & 2.0 & 4.0 & 6.0 & 8.0 \\
\hline \multicolumn{26}{|l|}{$\begin{array}{l}\text { All participants } \\
(\mathrm{n}=50)\end{array}$} \\
\hline Mean (mm) & 1.54 & 1.92 & 2.62 & 3.05 & 3.24 & 1.62 & 2.11 & 2.71 & 3.21 & 3.57 & 1.84 & 2.04 & 2.73 & 3.40 & 3.76 & 1.93 & 1.76 & 1.91 & 2.43 & 3.25 & 2.32 & 2.13 & 2.35 & 2.69 & 3.68 \\
\hline SD & 0.53 & 0.58 & 0.67 & 0.73 & 0.70 & 0.43 & 0.56 & 0.56 & 0.63 & 0.76 & 0.64 & 0.51 & 0.64 & 0.73 & 0.87 & 0.68 & 0.65 & 0.70 & 0.74 & 0.92 & 1.42 & 1.04 & 1.10 & 0.89 & 0.96 \\
\hline Median & 1.40 & 1.85 & 2.50 & 3.0 & 3.30 & 1.65 & 1.95 & 2.60 & 3.10 & 3.40 & 1.70 & 2.10 & 2.80 & 3.40 & 3.60 & 1.70 & 1.60 & 1.80 & 2.40 & 3.20 & 1.90 & 1.70 & 1,95 & 2,60 & 3,65 \\
\hline Min & 0.90 & 0.80 & 1.20 & 1.90 & 1.90 & 0.90 & 1.20 & 1.60 & 2.10 & 2.30 & 0.90 & 1.20 & 1.50 & 2.0 & 2.50 & 1.0 & 0.30 & 0.60 & 1.10 & 1.40 & 1.10 & 0.50 & 0.70 & 0.70 & 1.30 \\
\hline Max & 3.20 & 3.60 & 4.60 & 5.30 & 4.90 & 2.50 & 3.40 & 4.20 & 5.70 & 5.90 & 4.10 & 3.30 & 4.20 & 5.20 & 5.50 & 3.60 & 3.40 & 3.60 & 4.70 & 5.60 & 7.10 & 5.70 & 5.90 & 4.50 & 5.90 \\
\hline \multicolumn{26}{|l|}{ Male $(n=13)$} \\
\hline Mean (mm) & 1.71 & 2.11 & 2.85 & 3.30 & 3.70 & 1.70 & 2.11 & 2.90 & 3.50 & 3.99 & 1.96 & 2.09 & 2.79 & 3.58 & 4.05 & 1.85 & 1.71 & 2.18 & 2.72 & 3.75 & 2.08 & 2.05 & 2.43 & 2.93 & 3.87 \\
\hline SD & 0.62 & 0.68 & 0.99 & 0.90 & 0.75 & 0.40 & 0.56 & 0.62 & 0.84 & 1.09 & 0.73 & 0.56 & 0.65 & 0.88 & 0.93 & 0.57 & 0.63 & 0.79 & 0.96 & 0.89 & 0.82 & 0.82 & 0.85 & 0.93 & 0.90 \\
\hline Median & 1.50 & 2.00 & 2.20 & 3.10 & 3.60 & 1.50 & 2.20 & 2.80 & 3.20 & 3.70 & 1.70 & 1.80 & 2.60 & 3.50 & 4.10 & 1.70 & 1.60 & 1.80 & 2.80 & 3.50 & 1.90 & 1.60 & 1.90 & 3.10 & 3.70 \\
\hline Min & 0.90 & 1.20 & 1.90 & 2.30 & 2.20 & 1.20 & 1.40 & 2.20 & 2.60 & 2.30 & 1.30 & 1.60 & 1.90 & 2.40 & 2.90 & 1.10 & 0.90 & 1.20 & 1.30 & 1.90 & 1.30 & 1.30 & 1.60 & 0.90 & 2.20 \\
\hline $\operatorname{Max}$ & 3.20 & 3.60 & 4.60 & 5.30 & 4.90 & 2.40 & 3.40 & 4.20 & 5.70 & 5.90 & 3.90 & 3.20 & 4.20 & 5.20 & 5.40 & 2.90 & 3.10 & 3.60 & 4.70 & 5.10 & 4.40 & 4.10 & 4.20 & 4.50 & 5.50 \\
\hline \multicolumn{26}{|l|}{ Female $(n=37)$} \\
\hline Mean (mm) & 1.49 & 1.85 & 2.54 & 2.97 & 3.08 & 1.59 & 2.11 & 2.65 & 3.11 & 3.42 & 1.80 & 2.02 & 2.71 & 3.33 & 3.66 & 1.96 & 1.78 & 1.82 & 2.33 & 3.08 & 2.41 & 2.16 & 2.32 & 2.61 & 3.62 \\
\hline SD & 0.49 & 0.54 & 0.50 & 0.66 & 0.61 & 0.45 & 0.56 & 0.53 & 0.51 & 0.56 & 0.61 & 0.49 & 0.65 & 0.67 & 0.84 & 0.71 & 0.67 & 0.65 & 0.64 & 0.88 & 1.57 & 1.12 & 1.19 & 0.88 & 0.98 \\
\hline Median & 1.30 & 1.80 & 2.50 & 2.80 & 3.30 & 1.70 & 1.90 & 2.60 & 3.10 & 3.40 & 1.70 & 2.10 & 2.80 & 3.40 & 3.50 & 1.70 & 1.60 & 1.80 & 2.20 & 2.90 & 1.90 & 1.70 & 2.00 & 2.60 & 3.60 \\
\hline Min & 0.90 & 0.80 & 1.20 & 1.90 & 1.90 & 0.90 & 1.20 & 1.60 & 2.10 & 2.50 & 0.90 & 1.20 & 1.50 & 2.0 & 2.50 & 1.0 & 0.30 & 0.60 & 1.10 & 1.40 & 1.10 & 0.50 & 0.70 & 0.70 & 1.30 \\
\hline Max & 2.90 & 2.80 & 3.40 & 4.20 & 4.30 & 2.50 & 3.40 & 3.70 & 4.30 & 5.20 & 4.10 & 3.30 & 3.90 & 4.40 & 5.50 & 3.60 & 3.40 & 3.60 & 3.40 & 5.60 & 7.10 & 5.70 & 5.90 & 4.20 & 5.90 \\
\hline $\mathrm{p}$ & 0.19 & 0.25 & 0.91 & 0.36 & $0.01^{*}$ & 0.34 & 0.97 & 0.29 & 0.13 & 0.09 & 0.46 & 0.76 & 0.89 & 0.53 & 0.21 & 0.97 & 0.56 & 0.28 & 0.25 & $0.02^{*}$ & 0.82 & 0.75 & 0.36 & 0.19 & 0.52 \\
\hline
\end{tabular}




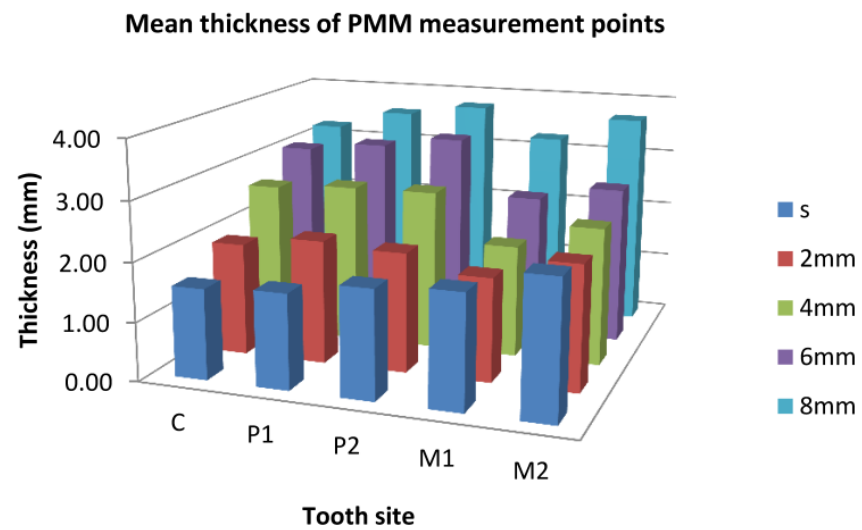

Figure 2. Mean thickness of 25 measurement points (in $\mathrm{mm}$ ) in the hard palate along sulcus level and 2, 4, 6, 8mm distant from gingival margin (position C and M2). S: Sulcus; PMM: Palatal masticatory mucosa; C: Canine, PI: First premolar; P2: Second premolar; MI: First molar; M2: Second molar.

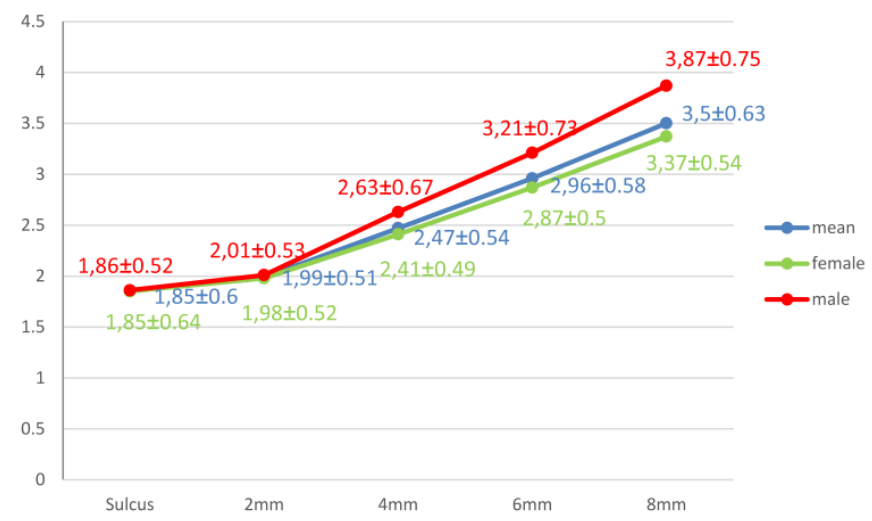

Figure 3. Mean thickness of the palatal mucosa at different heights of measurement and divided by gender.

\section{The buccal masticatory mucosa}

The mean thickness of mid-facial gingiva was found to be $1.11 \pm 0.39 \mathrm{~mm}$ while mean thickness of papilla-based gingiva was $3.15 \pm 0.66 \mathrm{~mm}$. Women had thinner mid-facial gingival thickness than those of men $(1.04 \pm 0.39 \mathrm{~mm}, 1.28 \pm 0.34 \mathrm{~mm}$, respectively) $(p=0.059)$. It was found to be significantly $(p<0.05)$ associated with overall PMM thickness $(\mathrm{r}=0.351)$, papilla-based gingival thickness $(\mathrm{r}=0.356)$, and mean tooth-related thicknesses at P1 ( $\mathrm{r}=0.278), \mathrm{M} 1(\mathrm{r}=0.313)$ and $\mathrm{M} 2(\mathrm{r}=0.379)$ regions.

The mean BMI value of the study population was $23.76 \pm 3.62 \mathrm{~kg} / \mathrm{m}^{2}$ while the median was $23.13 \mathrm{~kg} / \mathrm{m}^{2}$. The median was used to rank the study group as low and high BMI. There were no significant $(p>0.05)$ correlations between BMI and the mean thickness of palatal or buccal masticatory tissues except at $6 \mathrm{~mm}$ level of $\mathrm{C}(\mathrm{r}=0.502, \mathrm{p}<0.001)$ and $\mathrm{P} 1$ $(r=0.314, p=0.03)$ regions. Similarly, comparison of the mucosal thickness between individuals with low BMI
$23.13 \mathrm{~kg} / \mathrm{m}^{2}$ versus those with high BMI, failed to show a significant difference $(p=0.90)$. Women exhibited significantly lower mean BMI value than those of men $(\mathrm{p}=0.001)$.

\section{Discussion}

The present study was designed to evaluate the PMM in Turkish subjects with gingival deficiencies and to investigate the possible association of its thickness with different parameters. The mean thickness of PMM seemed to be similar but slightly thinner than those in previous reports with the same $[10,11$, 13] and different methods [16-18]. This may have resulted from the study population, measurement design and technique. Women had thinner (but not significant) ( $p>0.05)$ mucosa and significantly lower BMI indices $(p=0.001)$ than men. The skewed gender distribution in the study population may have affected the overall mean PMM thickness value. The PMM measurements have been performed on 5 different lines on the palate with the farthest at $8 \mathrm{~mm}$ away from the gingival margin. Most of the articles mapping the palatal mucosa selected deeper lines, which possibly changed or increased the overall mean value of PMM thickness [10-12, 17, 18]. The idea of having vertically the widest graft may not be valid anymore in order to cover the recession defect, especially considering the current mucogingival techniques which enable coronal mobilization of the recipient area $[25$, 26]. Additionally, it has been suggested that the variation in the anatomy of palatal vault and in location of neurovascular bundle may affect the dimensions of the donor tissue harvested $[27,28]$. Therefore, we designed the horizontal measurement lines in $2 \mathrm{~mm}$ intervals up to $8 \mathrm{~mm}$ from the gingival margin in order to map the safest and most available area of the hard palate.

The mean thickness of PMM varied at different regions of palate. There was an increase in PMM thickness towards the posterior and raphe palatina which is consistent with previous reports $[6,10-12,15$, 17] (Table 2). It has been histometrically shown that, the thickness of the lamina propria that comprises of dense connective tissue decreased towards the posterior palatal area and mid-palatal suture, while that of the submucosa including glandular and adipose tissue increased [14]. Additionally, the area adjacent to the palatal root of the $1^{\text {st }}$ molar, provided the thinnest PMM thickness and limited donor area for graft harvesting which was previously mentioned [12, 15]. Therefore, the optimum harvesting area has been shown as the region 3-9mm below the CEJ between the distal surface of the $C$ and the midline surface of M1 [14] which is confirmed by the present results. 
Table 2. Comparison of the results of current study and previous publications on PMM thickness.

\begin{tabular}{|c|c|c|c|c|c|c|c|c|c|}
\hline MP & Author & Technique & Ethnicity & $\mathbf{n}$ & $\mathrm{C}$ & P1 & P2 & M1 & M2 \\
\hline & & & & & \multicolumn{5}{|c|}{$m \pm s d$} \\
\hline Sulcus & Current & Direct (ER) & Caucasian $(\mathrm{T})$ & 50 & $1.54 \pm 0.53$ & $1.62 \pm 0.43$ & $1.84 \pm 0.64$ & $1.93 \pm 0.68$ & $2.32 \pm 1.42$ \\
\hline \multirow[t]{3}{*}{$2 \mathrm{~mm}$} & Current & Direct (ER) & Caucasian (T) & 50 & $1.92 \pm 0.58$ & $2.11 \pm 0.56$ & $2.04 \pm 0.51$ & $1.76 \pm 0.65$ & $2.13 \pm 1.04$ \\
\hline & Barriviera ${ }^{14}$ & СBCT & Mixed & 31 & $1.97 \pm 0.54$ & $2.07 \pm 0.46$ & $2.12 \pm 0.35$ & $2.11 \pm 0.51$ & $2.22 \pm 0.72$ \\
\hline & Wara-aswapati ${ }^{8}$ & Direct $(\mathrm{P})$ & Asian & 62 & $2.0 \pm 0.50$ & $2.10 \pm 0.50$ & $2.20 \pm 0.60$ & $2.10 \pm 0.70$ & $2.70 \pm 0.90$ \\
\hline \multirow[t]{2}{*}{$4 \mathrm{~mm}$} & Current & Direct (ER) & Caucasian (T) & 50 & $2.62 \pm 0.67$ & $2.71 \pm 0.56$ & $2.73 \pm 0.64$ & $1.91 \pm 0.70$ & $2.35 \pm 1.10$ \\
\hline & Müller12 & Ultrasonic & Caucasian & 40 & $2.32 \pm 0.63$ & $2.40 \pm 0.45$ & $2.33 \pm 0.45$ & $2.14 \pm 0.55$ & $2.44 \pm 0.89$ \\
\hline \multirow[t]{3}{*}{$6 \mathrm{~mm}$} & Current & Direct (ER) & Caucasian (T) & 50 & $3.05 \pm 0.73$ & $3.21 \pm 0.63$ & $3.40 \pm 0.73$ & $2.43 \pm 0.74$ & $2.69 \pm 0.89$ \\
\hline & Ueno 15 & СBCT & Asian & 44 & $4.04 \pm 1.32$ & $4.13 \pm 1.20$ & $4.07 \pm 1.19$ & $3.03 \pm 0.98$ & $2.77 \pm 1.35$ \\
\hline & Song13 & Spiral CT & Asian & 100 & $3.61 \pm 0.80$ & $3.84 \pm 0.76$ & $4.03 \pm 0.97$ & $3.08 \pm 0.80$ & $3.27 \pm 1.29$ \\
\hline \multirow[t]{5}{*}{$8 \mathrm{~mm}$} & Current & Direct (ER) & Caucasian $(\mathrm{T})$ & 50 & $3.24 \pm 0.70$ & $3.57 \pm 0.76$ & $3.76 \pm 0.87$ & $3.25 \pm 0.92$ & $3.68 \pm 0.96$ \\
\hline & Studer ${ }^{7}$ & Direct $(\mathrm{P})$ & Asian & 31 & $3.30 \pm 0.60$ & $3.90 \pm 0.60$ & $3.80 \pm 0.80$ & $3.50 \pm 1.30$ & $3.0 \pm 1.20$ \\
\hline & Müller 12 & Ultrasonic & Caucasian & 40 & $2.73 \pm 0.72$ & $2.88 \pm 0.55$ & $2.81 \pm 0.46$ & $2.12 \pm 0.58$ & $2.15 \pm 0.68$ \\
\hline & Barriviera14 & СBCT & Mixed & 31 & $3.48 \pm 0.69$ & $3.55 \pm 0.57$ & $3.85 \pm 0.59$ & $2.92 \pm 0.73$ & $3.08 \pm 1.22$ \\
\hline & Schacher ${ }^{10}$ & Direct $(C)$ & Caucasian & 33 & $5.11 \pm 1.07$ & $5.08 \pm 0.73$ & $5.17 \pm 0.80$ & $4.39 \pm 1.05$ & $5.75 \pm 1.78$ \\
\hline
\end{tabular}

MP: Measurement point; C: Canine; P1: First premolar; P2: Second premolar; M1: First molar; M2: Second molar; m: mean; sd: standard deviation; ER: Endodontic reamer; P: Periodontal probing; CT: Computerized tomography; CBCT: Cone beam computerized tomography; C: Sharp cannula; T: Turkish

The mean PMM thickness was not found to be related to gender, age or BMI value. Previously, it was correlated with age in studies in which the participants were relatively older $[11,16,17]$ compared to present subjects (mean: 27.4 years, range: 16-47) with an exception of reporting thicker PMM in younger subjects [13]. Similar to our findings, some articles did not find an effect of gender on PMM thickness [10,11] while others reported an effect $[8,12,13,16]$. This variation may be explained by differences in ethnicity and/or the measurement design of the studies. The studies reporting the difference mostly used relatively median areas for measurement where the PMM is usually thicker $[12,13]$. This was supported by the present findings, reporting a significant difference between the genders only at $8 \mathrm{~mm}$ from the gingival margin (Fig. 3). However, buccal masticatory mucosa thickness seems to be influenced by gender which is consistent with literature $[8,15,23]$. There was no association between BMI value and the mean thickness of palatal mucosa, except $6 \mathrm{~mm}$ from the margin. There are various reports regarding an association between BMI and the thickness of PMM [12, 13]. Our results supports the idea that in cases with high BMI, glandular and/or adipose tissue around the mid-palatal line may be more prominent [29].

This is the first study to investigate the thickness of PMM in a population with gingival deficiencies. These individuals are considered to have a thinner gingival biotype than individuals without gingival recessions [24, 30]. Our results confirm that the thickness of buccal masticatory mucosa correlates with PMM, which was previously reported [8].

Although several techniques have been reported to measure the thickness of masticatory mucosa we have chosen to sound the bone not only because it has been reported to be relatively reliable for measuring the tissue thickness [10], but also the same sites were used for harvesting grafts for gingival augmentation. The measurement error was reported to be $0.2 \mathrm{~mm}$ with this direct technique [10], while those with other "non-invasive" methods were $0.54 \mathrm{~mm}$ [6]. The possible disadvantages of the invasive methods have been an inspiration for the non-invasive methods such as ultrasonic devices [6, 15, 31], computed tomography $[16]$, or CBCT $[17,18]$. Although these methods may be less invasive, they have been reported to have difficulties such as obtaining consistently reliable results $[6,15,31]$, overestimation of thickness values resulting from low contrast resolution of images [18] the high radiation exposure [16] or intra-oral manipulation [7].

A sound knowledge of the anatomy of the palate is essential when harvesting SCTGs in order to prevent complications while obtaining the maximum amount of graft tissue possible [4, 5]. Transmucosal mapping of PMM is a practical, reliable, and inexpensive method in determining the safest and the most convenient area for graft harvesting procedures. It should be considered that subjects with gingival deficiencies may exhibit slightly thinner palatal masticatory mucosa. On this regard selection of the surgical procedure to augment the recessions may benefit from the information collected by transmucosal probing. The two major limitations of this study are the relatively small sample size and unequal gender distribution of the study population. Similar studies with more samples with even gender distribution are needed to make more concrete association of PMM thickness with that of age, sex, BMI and gingival biotype in patients with gingival recessions. 


\section{Conclusion}

The thickness of masticatory mucosa is crucial in making decisions for surgical treatment modality and may affect surgical outcome. It is important to map the PMM in a systematic manner with the safest and the most reliable method in order to decide the optimal harvesting site. Within the limits of this study, it may be speculated that the concept of tissue biotype may explain the association between the thickness of buccal and palatal masticatory mucosa.

\section{Competing Interests}

The authors have declared that no competing interest exists.

\section{References}

1. Kydd WL, Daly CH, Wheeler JB, 3rd. The thickness measurement of masticatory mucosa in vivo. International dental journal. 1971; 21: 430-41.

2. Wennstrom JL, Pini Prato GP. Mucogingival therapy - periodontal plastic surgery. In: Lindhe JKT, Lang NP, editor. Clinical Periodontology and Implant Dentistry; 4 ed. Oxford, UK: Blackwell Munksgaard. 2003: 576-631.

3. Harris RJ. Histologic evaluation of connective tissue grafts in humans. The International journal of periodontics \& restorative dentistry. 2003; 23:575-83.

4. Sanz M, Simion M, Working Group 3 of the European Workshop on P. Surgical techniques on periodontal plastic surgery and soft tissue regeneration: consensus report of Group 3 of the 10th European Workshop on Periodontology. Journal of clinical periodontology. 2014; 41 Suppl 15: S92-7. doi:10.1111/jcpe.12215

5. Zuhr O, Baumer D, Hurzeler M. The addition of soft tissue replacement grafts in plastic periodontal and implant surgery: critical elements in design and execution. Journal of clinical periodontology. 2014; 41 Suppl 15: S123-42. doi:10.1111/jcpe.12185

6. Muller HP, Schaller N, Eger T. Ultrasonic determination of thickness of masticatory mucosa: a methodologic study. Oral Surg Oral Med Oral Pathol Oral Radiol Endod. 1999; 88: 248-53.

7. Muller HP, Eger T. Masticatory mucosa and periodontal phenotype: a review. The International journal of periodontics \& restorative dentistry. 2002; 22 : $172-83$

8. Muller HP, Heinecke A, Schaller N, Eger T. Masticatory mucosa in subjects with different periodontal phenotypes. Journal of clinical periodontology. 2000; 27: 621-6.

9. Olsson M, Lindhe J, Marinello CP. On the relationship between crown form and clinical features of the gingiva in adolescents. Journal of clinical periodontology. 1993; 20: 570-7.

10. Studer SP, Allen EP, Rees TC, Kouba A. The thickness of masticatory mucosa in the human hard palate and tuberosity as potential donor sites for ridge augmentation procedures. Journal of periodontology. 1997; 68: 145-51. doi:10.1902/jop.1997.68.2.145

11. Wara-aswapati N, Pitiphat W, Chandrapho N, Rattanayatikul C, Karimbux N. Thickness of palatal masticatory mucosa associated with age. Journal of periodontology. 2001; 72: 1407-12. doi:10.1902/jop.2001.72.10.1407.

12. Stipetic J, Hrala Z, Celebic A. Thickness of masticatory mucosa in the human hard palate and tuberosity dependent on gender and body mass index. Collegium antropologicum. 2005; 29: 243-7.

13. Schacher B, Burklin T, Horodko M, Raetzke P, Ratka-Kruger P, Eickholz P. Direct thickness measurements of the hard palate mucosa. Quintessence Int. 2010; 41: e149-56.

14. Yu SK, Lee MH, Kim CS, Kim do K, Kim HJ. Thickness of the palatal masticatory mucosa with reference to autogenous grafting: a cadaveric and histologic study. The International journal of periodontics \& restorative dentistry. 2014; 34: 115-21. doi:10.11607/prd.1530.

15. Muller HP, Schaller N, Eger T, Heinecke A. Thickness of masticatory mucosa. Journal of clinical periodontology. 2000; 27: 431-6.

16. Song JE, Um YJ, Kim CS, Choi SH, Cho KS, Kim CK, et al. Thickness of posterior palatal masticatory mucosa: the use of computerized tomography. Journal of periodontology. 2008; 79: 406-12. doi:10.1902/jop.2008.070302.

17. Barriviera M, Duarte WR, Januario AL, Faber J, Bezerra AC. A new method to assess and measure palatal masticatory mucosa by cone-beam computerized tomography. Journal of clinical periodontology. 2009; 36: 564-8. doi:10.1111/j.1600-051X.2009.01422.x.

18. Ueno D, Sekiguchi R, Morita M, Jayawardena A, Shinpo S, Sato J, et al. Palatal mucosal measurements in a Japanese population using cone-beam computed tomography. Journal of esthetic and restorative dentistry : official publication of the American Academy of Esthetic Dentistry. 2014; 26: 48-58. doi:10.1111/jerd.12053.
19. Seibert JA, et al. Textbook of Clinical Periodontology and Implant Dentistry; 2 ed. Copenhagen: Munksgaard; 1989.

20. Olsson M, Lindhe J. Periodontal characteristics in individuals with varying form of the upper central incisors. Journal of clinical periodontology. 1991; 18: 78-82.

21. Muller HP, Kononen E. Variance components of gingival thickness. Journal of periodontal research. 2005; 40: 239-44. doi:10.1111/j.1600-0765.2005.00798.x.

22. Muller HP, Eger T. Gingival phenotypes in young male adults. Journal of clinical periodontology. 1997; 24: 65-71.

23. Vandana KL, Savitha B. Thickness of gingiva in association with age, gender and dental arch location. Journal of clinical periodontology. 2005; 32: 828-30. doi:10.1111/j.1600-051X.2005.00757.x.

24. Claffey N, Shanley D. Relationship of gingival thickness and bleeding to loss of probing attachment in shallow sites following nonsurgical periodontal therapy. Journal of clinical periodontology. 1986; 13: 654-7.

25. Aroca S, Keglevich T, Nikolidakis D, Gera I, Nagy K, Azzi R, et al. Treatment of class III multiple gingival recessions: a randomized-clinical trial. Journal of clinical periodontology. 2010; 37: 88-97. doi:10.1111/j.1600-051X.2009.01492.x.

26. Zuhr O, Fickl S, Wachtel H, Bolz W, Hurzeler MB. Covering of gingival recessions with a modified microsurgical tunnel technique: case report. The International journal of periodontics \& restorative dentistry. 2007; 27: 457-63.

27. Reiser GM, Bruno JF, Mahan PE, Larkin LH. The subepithelial connective tissue graft palatal donor site: anatomic considerations for surgeons. The International journal of periodontics \& restorative dentistry. 1996; 16: 130-7.

28. Monnet-Corti V, Santini A, Glise JM, Fouque-Deruelle C, Dillier FL, Liebart $\mathrm{MF}$, et al. Connective tissue graft for gingival recession treatment: assessment of the maximum graft dimensions at the palatal vault as a donor site. Journal of periodontology. 2006; 77: 899-902. doi:10.1902/jop.2006.050047.

29. Schroeder HE. Oral Structural Biology. New York: Thieme; 1991: 350-70.

30. Serino G, Wennstrom JL, Lindhe J, Eneroth L. The prevalence and distribution of gingival recession in subjects with a high standard of oral hygiene. Journal of clinical periodontology. 1994; 21: 57-63.

31. Uchida H, Kobayashi K, Nagao M. Measurement in vivo of masticatory mucosal thickness with $20 \mathrm{MHz}$ B-mode ultrasonic diagnostic equipment. Journal of dental research. 1989; 68: 95-100. 